\title{
BUDIDAYA DAN PENGOLAHAN JAMUR TIRAM BERBASIS MEDIA LIMBAH GERGAJI KAYU DAN BEKATUL UNTUK MENCIPTAKAN WIRAUSAHA BARU
}

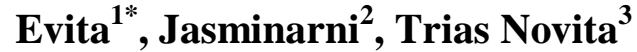 \\ ${ }^{1,2,3}$ Fakultas Pertanian, Universitas Jambi, Indonesia \\ Corresponding author: evitae@ymail.com
}

(Artikel Masuk: 04 Juni 2021; Artikel Diterima: 15 Juni 2021; Artikel Terbit: 25 Juni 2021)

\begin{abstract}
Oyster mushroom is one type of wood fungus which grows a lot on weathered wood media. Called oyster mushrooms because the shape of the hood is slightly rounded, oval and curved like an oyster shell. This activity aims to increase the knowledge and skills of farmers through counseling and demonstration of oyster mushroom cultivation technology and wood waste processing based on saws to find new entrepreneurs. In general, the output goal achieved that are direct are the results that can be directly felt by the community, especially Kelompok Tani Pabrika and Kelompok Tani D'Terong, as well as the surrounding community. Besides that, another target is to strive for the independence of farmer groups, especially in terms of providing oyster mushroom seeds, the baglog as a planting medium for their own groups and even expected to meet the needs of other oyster mushroom farmer seeds both in their own region and in other regions. So, the expected output is in the form of a product, namely good planting media (baglog) and food processing made from oyster mushrooms into typical food of Kerinci Regency. This method can help farmers in producing Oyster Mushroom products as a new entrepreneur, besides helping farmers in utilizing sawn wood waste which is usually burned, now it can be used as a medium for growing oyster mushrooms.
\end{abstract}

Keywords: Oyster mushrooms, Sawn wood waste, Entrepreneur

\begin{abstract}
Abstrak
Jamur tiram merupakan salah satu jenis jamur kayu karena jamur ini banyak tumbuh pada media kayu yang sudah lapuk. Disebut jamur tiram karena bentuk tudungnya agak membulat, lonjong dan melengkung seperti cangkang tiram. Kegiatan ini bertujuan untuk menambah pengetahuan dan keterampilan para petani melalui penyuluhan dan demonstrasi teknologi budidaya jamur tiram serta pengolahan limbah kayu berbasis media gergaji untuk menciptakan wirausaha baru. Secara umum target luaran yang dicapai yang bersifat langsung adalah hasilnya dapat langsung dirasakan masyarakat khususnya Kelompok Wanita Tani Pabrika dan Kelompok Wanita Tani D'Terong, serta masyarakat sekitar. Disamping itu target lain adalah mengupayakan kemandirian kelompok tani terutama dalam hal penyediaan bibit jamur tiram, baglog sebagai media tanam untuk kelompok sendiri bahkan juga diharapkan dapat memenuhi kebutuhan bibit petani jamur tiram lainnya baik di wilayah sendiri maupun wilayah lainnya. Jadi disini luaran yang diharapkan adalah berupa produk yaitu media penanaman (baglog) yang baik dan pengolahan makanan berbahan baku jamur tiram menjadi makanan khas Kabupaten Kerinci. Cara ini dapat membantu petani dalam menghasilkan produk Jamur tiram sebagai wirausaha baru, disamping itu membantu petani dalam pemanfaatan limbah kayu gergaji yang biasanya dibakar, sekarang bisa dimanfaatkan menjadi media tumbuh jamur tiram.
\end{abstract}

Kata kunci : Jamur tiram, Limbah kayu gergaji, Wirausaha 


\section{A. PENDAHULUAN}

Desa Koto Agung merupakan salah satu desa di Kecamatan Keliling Danau. Desa Koto Agung mempunyai luas wilayah $1.395 \mathrm{Ha}$, jumlah rumah tangga $244 \mathrm{KK}$ dengan jumlah penduduk 719 jiwa. Berdasarkan jenis kelamin penduduk dari laki-laki 379 jiwa dan perempuan 340 jiwa. Desa Koto Agung mempunyai 15 (lima belas) kelompok tani salah satunya adalah kelompok tani wanita Pabrika dan D'Terong yang masing-masing beranggotakan 10 orang. Mayoritas penduduknya bermata pencaharian sebagai Petani dengan komoditas andalan padi sawah dan perkebunan. Jarak Desa ini ke Ibu Kota Kecamatan adalah sekitar $1 \mathrm{Km}$ dan jarak ke Ibu Kota Kabupaten sekitar 21 $\mathrm{km}$.

Desa ini merupakan daerah yang ada di Propinsi Jambi, yang merupakan daerah pegunungan dengan ketinggian tempatnya kira-kira 1000-1600 m diatas permukaan laut, berhawa sejuk dengan curah hujan cukup tinggi. Dilihat dari keadaan iklimnya maka sangat mendukung sekali dalam membudidayakan jamur tiram yang butuh suhu dan kelembaban yang tinggi. Sementara itu di Kecamatan ini banyak terdapat pengrajin kayu yang menghasilkan banyak serbuk gergaji kayu yang selama ini limbah serbuk gergaji dibakar sehingga mencemari lingkungan.
Dengan adanya pengabdian ini limbah serbuk gergaji dapat dipakai sebagai media utama budidaya jamur tiram. Di samping itu di desa ini juga terdapat pengusaha penggilingan padi yang banyak menghasilkan bekatul, dimana bekatul ini juga digunakan sebagai campuran media budidaya jamur tiram. Campuran yang lain adalah TSP dan batu kapur/gamping yang relatif mudah diperoleh di desa ini.

Jamur tiram merupakan salah satu jenis jamur kayu karena jamur ini banyak tumbuh pada media kayu yang sudah lapuk. Disebut jamur tiram karena bentuk tudungnya agak membulat, lonjong dan melengkung seperti cangkang tiram. Batang atau tangkai jamur ini tidak tepat berada pada tengah tudung, tetapi agak ke pinggir (Cahyana, 1999) dan Chazali, et al 2010). Jamur tiram merupakan salah satu jamur yang enak dimakan dan mempunyai kandungan gizi yang cukup tinggi sehingga tidak mengherankan bila jenis jamur ini sekarang banyak dibudidayakan (Parjimo, dan Andoko. 2007)

Pengembangan jamur tiram merupakan usaha agroindustri yang memiliki potensi besar untuk dikembangkan karena dapat peningkatan penghasilan petani dan pertimbangan kesehatan, karena kandungan serat dalam jamur tiram dapat membantu proses pencernaan. Selain itu perkembangan usaha 
pembudidayaan jamur tiram saat ini sangat menggembirakan, karena jamur tiram memiliki berbagai manfaat yaitu; sebagai makanan, penurun kolesterol, lemah jantung, sebagai antibakteri dan anti tumor, serta dapat menghasilkan enzim hidrolisis (Widiastuti dan Tjokrokusumo, (2008)

Pengembangan budidaya dan pengolahan jamur tiram di Desa Koto Agung Kecamatan Keliling Danau akan memberikan prospek yang bagus dan dapat meningkatkan pendapatan keluarga, karena jamur tiram masih banyak diperlukan, sementara pengusaha Jamur tiram jumlahnya masih sedikit. Kedepannya diharapkan upaya budidaya jamur tiram yang berbasis rumah tangga ini dapat menjadi salah satu alternatif usaha dalam meningkatkan pendapatan masyarakat. Budidaya jamur tiram dapat dilakukan dalam skala kecil untuk industri rumah tangga karena tidak memerlukan tempat yang luas atau sebagai usaha sampingan keluarga.

Hal ini didasarkan pada kondisi real masyarakat yang sangat menggemari jamur baik sebagai lauk makan nasi maupun sebagai cemilan.

Selama ini jamur tiram biasa dijual dalam bentuk basah tanpa diolah, melalui pengabdian ini diharapkan dapat dilakukan diversifikasi produk olahan jamur tiram lainnya, sehingga menambah aneka macam makanan yang berbahan baku jamur tiram.
Hal ini juga akan membantu para wisatawan dalam menemukan oleh-oleh khas dari daerah Kerinci, sehingga akan menyebabkan nilai jual jamur tiram meningkat. Keadaan ini akan membantu untuk lebih meningkatkan perekonomian masyarakat desa setempat.

\section{B. PELAKSANAAN DAN METODE}

Pelaksanaan kegiatan Pengabdian pada Masyarakat ini dilaksanakan di Desa Koto Agung dengan dua kelompok tani yaitu kelompok wanit tani Pabrika dan kelompok wanita tani D'Terong selama lebih kurang 6 bulan. Kegiatan ini dibagi menjadi 3 tahapan yaitu : Pengenalan program, Kegiatan penyuluhan dan demontrasi serta pelatihan/praktek terhadap kedua kelompok tani

\section{Pengenalan Program}

Pada tahap ini tim pengabdian masyarakat memperkenalkan rencana kegiatan pengabdian pada kelompok petani jamur, menjelaskan detail kegiatan yang akan dilakukan yang telah disepakati bersama. Pada tahap ini dibuat kesepakatan pengaturan waktu dan jadwal pelaksanaan, penyampaian materi (penyuluhan) dan demontrasi pelaksanaan tekhnik budidaya jamur tiram. Hal ini dilakukan agar seluruh anggota kelompok tani dapat berpartisipasi dalam seluruh program yang direncanakan, menjamin pemerataan dan penyebaran ilmu 
pengetahuan dan ketrampilan pada petani jamur.

\section{Kegiatan Penyuluhan}

Penyuluhan dalam bentuk ceramah tentang teknik budidaya dan pengolahan jamur tiram dengan memanfaatkan limbah kayu gergaji dan bekatul, materi yang diberikan meliputi cara pembuatan media tempat tumbuhnya jamur (baglog), penanaman, pemeliharaan serta panen dan pasca panen jamur tiram. Penyuluhan tentang pengolahan diawali dari panen yang tepat, sortasi, pembersihan dan pengolahan dengan menjelaskan berbagai resep olahan jamur tiram menjadi berbagai produk makanan.

\section{Program Demontrasi dan Pembinaan}

Kegiatan ini adalah kegiatan inti dari kegiatan yang dilaksanakan oleh tim pengabdian karena pada kegiatan ini nantinya petani akan dapat mempraktekkan dan melihat langsung semua kegiatan yang akan diterapkan pada budidaya jamur tiram dan pembuatan makanan yang berbahan baku jamur tiram. Kegiatan demontrasi dan pembinaan ini dibagi atas :

a. Penyuluhan dalam bentuk ceramah dan demontrasi tentang teknologi budidaya jamur tiram skala rumah tangga pada kelompok tani wanita Paprika dan kelompk tani wanita D'Terong pelatihan dilakukan selama 3 hari, materi yang akan diberikan meliputi pembibitan, penanaman pemeliharaan serta panen dan pasca panen.

b. Pendampingan pembuatan penyediaan bibit inokulan, pembuatan media, sterilisasi media kontrol kelembaban, penanganan hama dan penyakit serta pembuatan baglog.

c. Pendampingan pembuatan kumbung budidaya jamur tiram skala rumah tangga d. Pelatihan dan demontrasi pengolahan makanan berbahan baku jamur tiram. e. Pelatihan, praktek dan pendampingan pengolahan makanan berbahan baku jamur tiram siap jual

f. Pembentukan Kelompok Usaha Bersama budidaya dan pengolahan jamur tiram g. Perintisan usaha pemasaran makanan berbahan baku jamur tiram.

\section{HASIL DAN PEMBAHASAN}

Program pengabdian ini berupaya memberi solusi untuk memanfaatkan limbah serbuk gergaji kayu dan bekatul sebagai media budidaya jamur tiram. Hasil observasi yang dilakukan di desa ini banyak terdapat pengrajin kayu yang menghasilkan banyak serbuk gergaji kayu dan terdapat pengusaha penggilingan padi yang banyak menghasilkan bekatul. Selama ini limbah serbuk gergaji dan bekatul dibiarkan menumpuk ditempat pembuangannya kemudian dibakar sehingga mencemari lingkungan. 
Setelah adanya penyuluhan tentang manfaat dari limbah gergaji kayu sebagai media budidaya jamur tiram, kelompok wanita tani (Paprika dan D'Terong) mulai punya perhatian apalagi mereka juga menerima semacam informasi bahwa jamur tiram juga bisa diolah menjadi bermacammacam makanan olahan seperti jamur tiram crispy, nugget jamur tiram dan bakso jamur tiram. Demikian juga nilai jual yang cukup menjanjikan ini membuat masyarakat atau kelompok tani mulai menaruh perhatian untuk membudidayakan jamur tiram. Untuk budidaya jamur tiram mereka kesulitan dengan bibit dan media tumbuh, karena selama ini media yang sudah di inokulasi dengan bibit jamur tiram dibeli dari luar daerah. Program pengabdian ini berupaya memberi solusi untuk mendapatkan bibit dan media tumbuh yang baik dengan melakukan penyuluhan, pelatihan dan demontrasi bagaimana mendapatkan teknologi budidaya dan pengolahan Jamur tiram berbasis media limbah gergaji kayu untuk menciptakan wirausaha baru. Penyuluhan yang diberikan dapat menambah pengetahuan kedua kelompok wanita tani tentang manfaat limbah serbuk gergaji sebagai media tumbuh jamur tiram dengan harapan agar dapat ditularkan pada kelompok tani atau masyarakat lainnya. Kelompok tani sangat antusias dalam menerima semua pelatihan yang diberikan. Demontrasi pembuatan media tumbuh jamur tiram (baglog) ini langsung dipraktekan bersama kelompok wanita tani, sehingga mereka dapat mencoba langsung di lapangan. Begitu juga ibu-ibu kelompok wanita tani telah mempraktekkan langsung pengolahan makanan ringan yang berbahan baku jamur tiram yang bisa disimpan cukup lama seperti pembuatan jamur tiram crispy, bakso jamur tiram dan lain-lainnya. Kelompok ini nantinya diharapkan dapat memproduksi makanan-makanan yang berbahan baku jamur tiram sebagai salah satu oleh-oleh khas dari Kabupaten Kerinci. Pelatihan dilakukan dengan cara melatih diri dengan dengan membudidayakan jamur tiram, dalam skala kecil untuk industri rumah tangga,karena tidak memerlukan tempat yang luas atau sebagai usaha sampingan keluarga yang nantinya mampu memberikan tambahan pendapatan keluarga, kumbung jamur tiram dengan ukuran $21 \mathrm{~m}^{2}$ saja dapat berisi 600 baglog jamur yang mampu menghasilkan 300-350 $\mathrm{kg}$ jamur tiram dapat mereka jual di pasar tradisional dengan harga jual Rp20000,00 $\mathrm{Rp} 25000,00$ / kg.

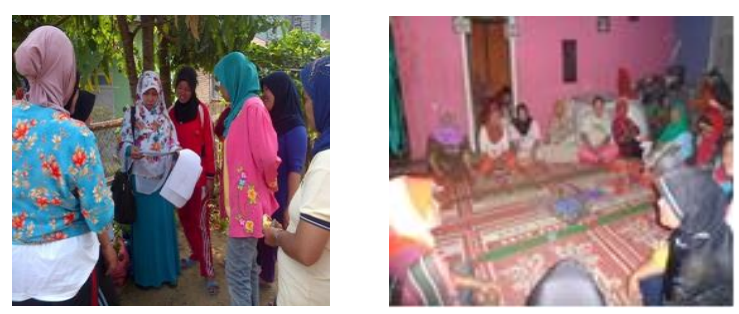

Gambar 1. Pertemuan dengan kelompok 

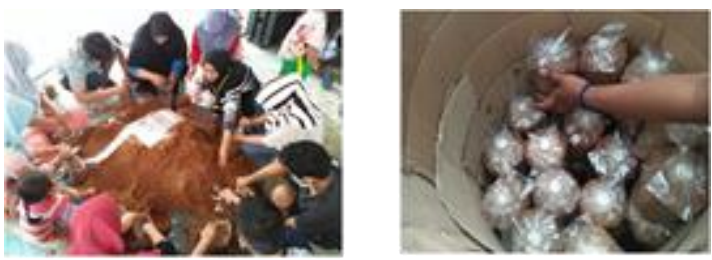

Gambar 2. Pembuatan media tanam (baglog)
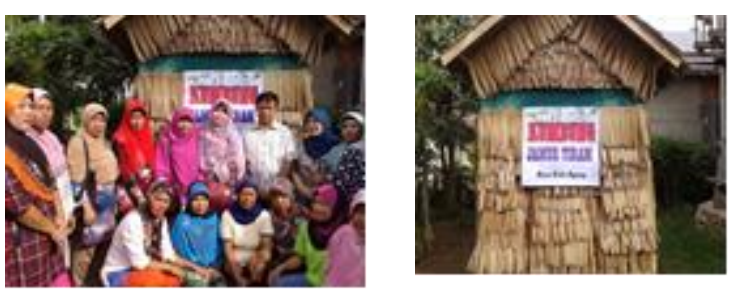

Gambar 3. Monev dari LPPM dan Kumbung jamur
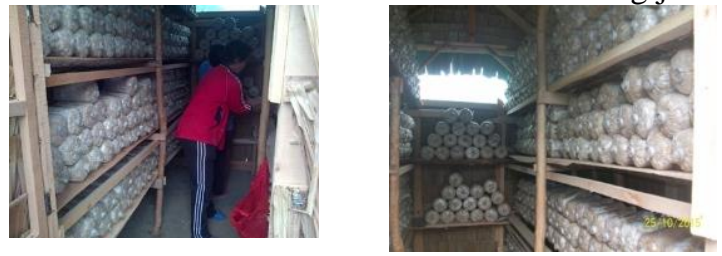

Gambar 4. Baglog Jamur Tiram
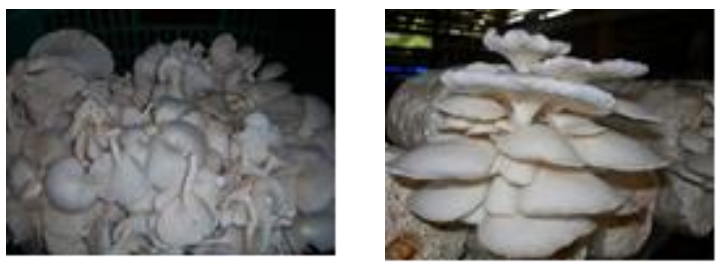

Gambar 5. Jamur Tiram
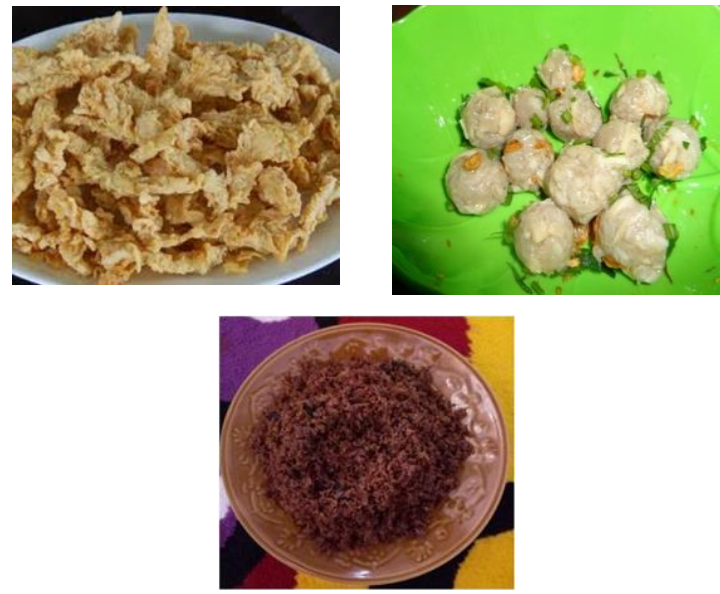

Gambar 6. Olahan makanan berbahan baku jamur tiram

Dengan demikian mereka dapat menghasilkan jamur tiram sendiri dan agar jamur tiram bisa tahan lama mereka bias mengolah jamur tiram menjadi bahan makanan ringan, dari hasil penjualan ini dapat membantu dalam memperbaiki ekonomi keluarga. Kegiatan yang sudah dilaksanakan selama pengabdian ini dapat dilihat pada Gamba 1-6.

\section{PENUTUP}

\section{Kesimpulan}

1. Budidaya jamur tiram berbasis media limbah gergaji kayu dapat dan berhasil dilakukan oleh kelompok tani dan akan diperkenalkan pada masyarakat sekitarnya.

2. Meningkatnya pengetahuan dan pemahaman serta skill kelompok tani dalam budidaya jamur tiram .

3. Teknik pengolahan makanan berbahan baku jamur tiram dapat dijadikan sebagai salah satu oleh-oleh khas dari Kabupaten Kerinci.

\section{Saran}

Kelompok tani di harapkan dapat menyebar luaskan tentang teknologi budidaya dan pengolahan jamur tiram berbasis media limbah gergaji kayu ini pada masyarakat umumnya atau kelompok tani khususnya untuk menciptakan wirausaha baru sehingga program ini keberlanjutannya tetap terjaga.

\section{Ucapan Terima Kasih}




\section{E. DAFTAR PUSTAKA}

Cahyana, Y.A. 1999. Jamur Tiram. Penebar Swadaya. Jakarta.

Chazali, Syammahfuz dan S. P, Putri. 2010. Usaha Jamur Tiram. Jakarta. Penebar Swadaya.

Parjimo, H dan A. Andoko. 2007. Budidaya Jamur (Jamur Kuping, Jamur Tiram dan Jamur Merang). Agro Media Pustaka. Jakarta.

Widyastuti, N. dan D. Tjokrokusumo 2008. Aspek Lingkungan Sebagai Faktor Penentu Keberhasilan Budidaya Jamur Tiram. (Pleurotus Sp). Jurnal Teknologi Lingkungan 9 (3). Hal. 287 - 293 